\title{
Ação sonoquímica e influência das condições de tratamento térmico na preparação de cimentos do sistema binário $\mathrm{CaO}-\mathrm{Al}_{2} \mathrm{O}_{3}$
}

\section{(Sonochemical action and the influence of heat treatment conditions on the preparation of cements of the $\mathrm{CaO}-\mathrm{Al}_{2} \mathrm{O}_{3}$ binary system)}

\author{
R.R. Lourenço ${ }^{1}$, C.C.D. Exposito ${ }^{1}, R . S$. Angélica $^{2}, J . A$. Rodrigues $^{1}$ \\ ${ }^{1}$ Grupo de Engenharia de Microestrutura de Materiais - GEMM, Departamento de Engenharia de Materiais \\ Universidade Federal de S. Carlos, Rod. Washington Luiz, km 235, C.P. 676, S. Carlos, SP 13565-905 \\ ${ }^{2}$ Instituto de Geociências, Universidade Federal do Pará, Belém, PA \\ josear@ufscar.br
}

\begin{abstract}
Resumo
Foram preparados cimentos do sistema binário $\mathrm{CaO}-\mathrm{Al}_{2} \mathrm{O}_{3}$ por meio de uma rota que emprega o processo sonoquímico seguido de tratamento térmico. Convencionalmente estes compostos são fabricados a partir da fusão ou da sinterização de uma mistura de calcário com bauxito ou com alumina. O maior inconveniente associado a este tipo de síntese é a necessidade de temperaturas elevadas e o grande consumo de energia. Na rota sonoquímica a cálcia, juntamente com a alumina em suspensão aquosa, são introduzidas num banho de ultra-som por tempo determinado. Em seguida, após a evaporação da água, o material resultante é tratado termicamente. Quando um sistema é submetido ao processo sonoquímico, alterações na morfologia superficial das partículas podem ser induzidas pelas ondas ultra-sônicas, incluindo a redução do tamanho dessas partículas. Como conseqüência, estes materiais tornam-se mais reativos, facilitando a síntese final dos aluminatos de cálcio durante o tratamento térmico. Foi estudada a ação das ondas ultra-sônicas e a influência das condições de tratamento térmico em duas composições molares de cálcia:alumina de 1:1 e 1:2. As temperaturas empregadas foram $1000{ }^{\circ} \mathrm{C}, 1200{ }^{\circ} \mathrm{C}$ e $1300{ }^{\circ} \mathrm{C}$ com patamares de 1 e $6 \mathrm{~h}$. O material obtido foi caracterizado por microscopia eletrônica de varredura, difração de raios X e as fases presentes foram semi-quantificadas pelo método de Rietveld. Também foram realizados ensaios de compressão diametral para avaliar a resistência mecânica dos produtos da síntese. Foram preparadas pastas constituídas de cimento, alumina e água, utilizando como cimento os aluminatos de cálcio preparados pelo processo sonoquímico e um cimento comercial, como referência.
\end{abstract}

Palavras-chave: síntese, sonoquímica, tratamento térmico, cimento de aluminato de cálcio.

\begin{abstract}
Cements of the $\mathrm{CaO}-\mathrm{Al}_{2} \mathrm{O}_{3}$ binary system were prepared through a sonochemical process at room temperature followed by heat treatment. The conventional production consists of a reaction in which a stoichiometric mixture of lime and bauxite or alumina is melted or sintered. High temperatures and energy consumption is an inconvenience associated to this type of synthesis. In the sonochemical process, the initial reagents, calcia and alumina, are put in an aqueous suspension under the action an ultrasonic bath during some time. After that, the material is heat treated, after the evaporation of water. Ultrasonic waves can induce changes in the surface morphology of the particles, including size reduction of them. Consequently, the reagent particles become more reactive and this facilitates the final synthesis of the calcium aluminates during the heat treatment. The action of ultrasonic waves and the influence of thermal treatment conditions were studied on two initials molar compositions calcia:alumina of 1:1 and 1:2. Temperatures of 1000, 1200 and $1300{ }^{\circ} \mathrm{C}$ for 1 and $6 \mathrm{~h}$ were employed. SEM and X-ray diffraction were used to characterize the obtained materials and the phases were semi-quantified through Rietveld method. In addition, mechanical strength of the products was evaluated through splitting tensile tests. Pastes consisting of cement, alumina and water were prepared using the calcium aluminates prepared through the sonochemical process and commercial cement as reference.
\end{abstract}

Keywords: synthesis, sonochemistry, heat treatment, calcium aluminate cement.

\section{INTRODUÇÃO}

Os compostos do sistema binário cálcia-alumina $(\mathrm{CaO}-$ $\mathrm{Al}_{2} \mathrm{O}_{3}$ ), além de apresentarem propriedades refratárias e bom desempenho em ambientes corrosivos, possuem fases com excelente capacidade de hidratação. Estas fases quando em contato com a água formam hidratos que possuem estruturas capazes de conferir ao material resistência mecânica considerável em temperatura ambiente. Sendo assim, estes aluminatos de cálcio, são utilizados como agentes ligantes em concretos refratários. Concretos refratários são materiais cerâmicos capazes de resistir aos efeitos térmicos, químicos 
e físicos sem fundir ou mesmo se deformar, mantendo o seu desempenho em temperaturas elevadas. O principal foco de aplicação dos concretos refratários concentra-se no revestimento de equipamentos industriais que operam em temperaturas elevadas $[1,2]$. Os cimentos aluminosos são preparados através de processos similares aos processos empregados na preparação industrial do cimento Portland. O material com a composição mineralógica específica e estequiometricamente dosada é submetido a processos de redução granulométrica, obtendo-se assim um pó fino e homogêneo, facilitando as reações químicas que ocorrem pelo incremento da superfície de contato. Em seguida, este pó é fundido ou sinterizado no interior de fornos especiais. Nesta etapa ocorrem alterações profundas na composição química e mineralógica do material bruto, dando lugar a um produto com características qualitativamente novas conhecido como clínquer. A fase final do processo consiste na preparação efetiva do cimento. Nesta etapa ocorrem operações de mistura do clínquer com aditivos, nas proporções estabelecidas para o cimento desejado, seguidas da moagem e embalagem do produto para a venda [3].

A eletrofusão é utilizada por algumas fabricas de produção de cimentos nos países onde a energia elétrica é relativamente barata. Entretanto, a sinterização das matérias-primas em fornos rotativos tem provado ser o meio mais viável de produzir cimentos de diversos tipos de purezas conhecidos como cimento de alta, intermediária e de baixa alumina. $\mathrm{O}$ maior inconveniente associado a estes tipos de síntese é a necessidade de temperaturas elevadas e o grande consumo de energia $[2,3]$. O produto resultante desses métodos de preparação não é composto por uma única fase. Geralmente, apresentam diferentes fases do sistema cálcia-alumina em teores diversos, juntamente com $\mathrm{CaO}$ e $\mathrm{Al}_{2} \mathrm{O}_{3}$, que não reagiram durante o processo. Pode também conter alguma fase indesejável formada devido às impurezas que possam estar presentes nas matérias-primas. Os constituintes mais importantes dos cimentos de aluminato de cálcio, CAC, já em ordem decrescente de concentração, são o monoaluminato de cálcio $\left(\mathrm{CaAl}_{2} \mathrm{O}_{4}: \mathrm{CA}\right)$, o dialuminato de cálcio $\left(\mathrm{CaAl}_{4} \mathrm{O}_{7}: \mathrm{CA}_{2}\right)$ e a maienita $\left(\mathrm{Ca}_{12} \mathrm{Al}_{14} \mathrm{O}_{33}: \mathrm{C}_{12} \mathrm{~A}_{7}\right)[1,2,4]$. A fase CA é o componente mais importante dos cimentos aluminosos. Além, de desenvolver maior resistência mecânica durante um período relativamente curto do tempo disponível para a hidratação de um concreto refratário, possui ponto de fusão relativamente alto, aproximadamente $1600{ }^{\circ} \mathrm{C}$. Embora, a fase $\mathrm{CA}_{2}$ se decomponha numa temperatura superior $\left(1750^{\circ} \mathrm{C}\right)$, ela não pode atuar como o componente principal do CAC, pois o tempo de endurecimento é muito longo e gera uma resistência mecânica inferior. No entanto, a presença do $\mathrm{CA}_{2}$ pode acelerar o processo de pega da fase CA e por esse motivo, ele aparece nos cimentos aluminosos como fase secundária. Já a fase $\mathrm{C}_{12} \mathrm{~A}_{7}$ apresenta uma temperatura de fusão relativamente baixa $\left(\sim 1430^{\circ} \mathrm{C}\right)$; porém, se hidrata e endurece rapidamente. Sendo assim, este componente pode ser utilizado para controlar a taxa de endurecimento de cimentos comerciais [2,4].

No processo de sinterização, os aluminatos de cálcio são formados por reação no estado sólido, que é conduzida a partir do mecanismo de difusão química que ocorre entre os reagentes. Este transporte é facilitado pelo aumento da área da interface de contato entre as partículas sólidas e pelo aumento da temperatura. Na rota convencional de preparação, forma-se inicialmente uma fase rica em $\mathrm{CaO}$ que com o aumento da temperatura ou com o decorrer do tempo, reage com o $\mathrm{Al}_{2} \mathrm{O}_{3}$ disponível formando a fase de interesse. Por exemplo, para se preparar a fase CA, cálcia e alumina são misturadas em proporções molares de 1:1 e aquecidas entre 1200 e $1400{ }^{\circ} \mathrm{C}$. Todas as outras fases termodinamicamente estáveis e com maiores teores de óxido de cálcio se formam inicialmente. Com o tempo de reação ou com o aumento da temperatura, estas fases se convertem para a fase de interesse, neste caso o monoaluminato de cálcio $[5,6]$.

Com a finalidade de se preparar aluminatos de cálcio em temperaturas mais baixas que as empregadas nos processos convencionais, métodos alternativos de síntese são alvo crescente de pesquisa. No processo conhecido como sonoquímica, os reagentes, inicialmente em suspensão, são expostos a ondas ultra-sônicas. Quando um sistema químico é submetido a esse tipo de onda, significativas alterações químicas e físicas podem ocorrer no material, viabilizando assim o processo químico de interesse. O tratamento ultra-sônico de sistemas líquido-sólido é capaz de induzir, entre outros efeitos benéficos, mudanças na morfologia superficial, na composição e na reatividade do material particulado. Sendo assim, espera-se que o tratamento ultrasônico induza mudanças morfológicas na superfície tanto da alumina quanto da cálcia, tornando-as mais reativas e com isso, obter-se os aluminatos de cálcio empregandose temperaturas mais baixas do que aquelas utilizadas nas rotas convencionais [7-9]. Baseado nestas considerações e partindo-se de duas composições molares entre a cálcia e a alumina de 1:1 e 1:2, aluminatos de cálcio foram preparados a partir do processo sonoquímico seguido de tratamento térmico. Estudou-se tanto a ação das ondas ultra-sônicas quanto a influência das condições de tratamento térmico no aparecimento das fases do sistema cálcia-alumina.

\section{MATERIAIS E MÉTODOS}

Para a síntese dos aluminatos de cálcio foram utilizados óxido de cálcio P.A. (Vetec) e alumina A50 (Alcoa Alumínio S.A., Poços de Caldas, MG). As composições químicas dessas matérias-primas estão mostradas, respectivamente, nas Tabelas I e II. Destaca-se, no caso da A50, os 9,76\% de perda devido à umidade e hidratos presentes nessa matériaprima.

O óxido de cálcio foi previamente calcinado a $1000{ }^{\circ} \mathrm{C}$ por $1 \mathrm{~h}$. A alumina não passou por tratamento prévio. As matériasprimas foram estequiometricamente pesadas conforme a fase do aluminato de cálcio desejada, ou seja, com as proporções molares cálcia:alumina de 1:1 para a fase CA e de 1:2 para o $\mathrm{CA}_{2}$. $\mathrm{O}$ teor de óxido de alumínio na alumina A50 foi considerado na formulação das composições. O fator de correção utilizado foi determinado a partir da 
Tabela I - Composição química do $\mathrm{CaO}$ fornecida pelo fabricante.

[Table I - Chemical composition of $\mathrm{CaO}$ given by the producer.]

\begin{tabular}{cc}
\hline Componentes & \%-p \\
\hline $\mathrm{CaO}$ & Min. 95 \\
Sulfato $\left(\mathrm{SO}_{4}\right)$ & Máx. 0,5 \\
Ferro $(\mathrm{Fe})$ & Máx. 0,1 \\
Cloreto $(\mathrm{Cl})$ & Máx. 0,05 \\
Metais Pesados (como Pb) & Máx. 0,005 \\
Perda por Ignição & Máx. 3 \\
\hline
\end{tabular}

Tabela II - Composição química da alumina A50 fornecida pelo fabricante.

[Table II - Chemical composition of A50-alumina given by the producer.]

\begin{tabular}{cc}
\hline Componentes & $\%$-p \\
\hline $\mathrm{MnO}$ & 0,0007 \\
$\mathrm{Fe}_{2} \mathrm{O}_{3}$ & 0,031 \\
$\mathrm{CaO}$ & 0,079 \\
$\mathrm{SiO}_{2}$ & 0,096 \\
$\mathrm{Na}_{2} \mathrm{O}$ & 1,260 \\
$\mathrm{Al}_{2} \mathrm{O}_{3}$ & 90,293 \\
\hline & \\
$\mathrm{LOI}$ & 5,03 \\
$\mathrm{U} 300$ & 3,21 \\
$\mathrm{U} 110$ & 1,52 \\
\hline
\end{tabular}

LOI: perda de massa de 300 a $1000{ }^{\circ} \mathrm{C}$; U110: perda de umidade a $110{ }^{\circ} \mathrm{C}$; U300: perda de umidade a $300{ }^{\circ} \mathrm{C}$.

análise termogravimétrica da A50, a ser apresentado mais à frente. Preparou-se uma suspensão aquosa misturandose manualmente os pós, cálcia e A50, com água destilada. A relação água/sólidos utilizada foi de aproximadamente 30/1. Esta suspensão foi submetida a um banho ultra-sônico (Ultrasonic Cleaner Thornton, $25 \mathrm{kHz}, 1800 \mathrm{~W}$ ) por $1 \mathrm{~h}$ em temperatura ambiente. Para que o efeito sonoquímico fosse mais efetivo em toda a suspensão, foram feitas agitações periódicas durante o processo [9]. Finalmente, a suspensão foi seca em estufa de $110^{\circ} \mathrm{C}$ por $24 \mathrm{~h}$. O material sólido resultante foi macerado e em seguida submetido ao tratamento térmico. Para se verificar a ação das ondas ultra-sônicas sobre este sistema, uma amostra de cada composição, $\mathrm{CA}$ e $\mathrm{CA}_{2}$, após o processo sonoquímico, foi tratada termicamente a $1000{ }^{\circ} \mathrm{C}$ durante $1 \mathrm{~h}$, juntamente com amostras de ambas as composições que não foram expostas ao ultra-som. Neste último caso, a cálcia e a alumina foram pesadas nas devidas proporções molares e colocadas num almofariz, no qual foram misturadas manualmente com o auxilio de um pistilo, para melhor homogeneização dos pós, antes do tratamento térmico. Para a verificação da influência da temperatura e do tempo de tratamento térmico na síntese dos cimentos, amostras de cada composição, $\mathrm{CA}$ e $\mathrm{CA}_{2}$, foram submetidas às temperaturas de 1000,1200 e $1300{ }^{\circ} \mathrm{C}$ e para cada uma dessas, foram empregados dois tempos de duração, 1 h e 6 h.

As fases dos aluminatos de cálcio nas amostras tratadas termicamente foram identificadas a partir dos seus difratogramas de raios X. Para a análise do material em pó foi utilizado um difratômetro Rigaku Rotaflex RU-200B, com radiação $k_{\alpha}$ do cobre, com filtro de $\mathrm{Ni} \mathrm{e}$ ângulo de varredura $2 \theta$ variando entre 10 e $75^{\circ}$. As análises semi-quantitativas foram feitas em um difratômetro de raios X PANalytical X'Pert, também com radiação $\mathrm{k}_{\alpha}$ do $\mathrm{Cu}$ e filtro de $\mathrm{Ni}$, e intervalo de varredura de 5 a $80^{\circ} 2 \theta$. O detector utilizado é do tipo RTMS $\mathrm{X}^{\prime}$ Celerator, detector linear de estado sólido com 128 canais. Como não há fenda de recepção, cada canal se comporta como uma fenda de recepção, ou 128 detectores paralelos. Por isso a coleta de dados é realizada em tempo mais rápido do que em equipamentos com detectores convencionais. A grande vantagem é a obtenção de altas contagens, fundamentais para o refinamento pelo método de Rietveld. Há uma fenda divergente de $1 / 2^{\circ}$ no feixe incidente, seguida de uma fenda de anti-espalhamento com o dobro da abertura.

Para se observar a morfologia das matérias-primas, do material obtido após o processo sonoquímico e do material resultante do tratamento térmico, foram feitas fotos num equipamento de microscopia eletrônica de varredura, Zeiss DSM960, operando com $20 \mathrm{kV}$, em modo elétrons secundários. As amostras em pó foram recobertas com ouro num equipamento de sputtering Balzers SCD50.

Para avaliar o desempenho mecânico dos produtos da síntese foram feitos ensaios de compressão diametral, pelos quais pode-se inferir sobre a coesão dos materiais, já que as tensões predominantes, nesse teste, são de tração. Foram confeccionados corpos de prova cilíndricos de $2 \mathrm{~cm}$ x 2 $\mathrm{cm}$, misturando-se 50\%-p de alumina calcinada A1000 SG (Almatis), 50\%-p do material sintetizado e água destilada, com uma relação água/cimento de 0,8 . Os corpos de prova foram conformados em moldes de pvc e em seguida curados em câmara climática com $100 \%$ de umidade relativa a $50{ }^{\circ} \mathrm{C}$ durante $72 \mathrm{~h}$. Foram, então, desmoldados e secos por mais $72 \mathrm{~h}$ em estufa a $50{ }^{\circ} \mathrm{C}$. As condições de cura e a relação água:cimento foram rigorosamente controladas. Depois de secos, os corpos de prova foram mantidos em dessecadores até a realização dos ensaios mecânicos. A resistência à compressão diametral foi obtida empregando-se uma máquina universal de ensaios mecânicos, servo-hidráulica, MTS 810, com controle TestStar IIs, de acordo com a norma ASTM C496-90 (Splitting Tensile Strength of Cylindrical Concrete Specimens). Os ensaios foram realizados para 5 corpos-de-prova para cada tipo de amostra. Também foram preparados corpos de prova utilizando como referência um cimento refratário comercial, Secar 71 (Lafarge). Os resultados desses testes foram comparados, com a finalidade de se verificar o desempenho dos produtos gerados neste trabalho. 


\section{RESULTADOS E DISCUSSÃO}

\section{Matérias-primas}

Sintetizaram-se os cimentos pertencentes ao sistema cálcia-alumina a partir de uma matéria-prima comercial de elevada pureza, a cálcia, e de uma matéria-prima como fonte de alumina denominada de A-50, da Alcoa Alumínio S.A., de Poços de Caldas-MG.A Fig. 1 mostra os difratogramas de raios X da cálcia após a calcinação e da alumina A50, como recebida. Enquanto a cálcia apresenta em sua composição uma única fase cristalina, o óxido de cálcio com estrutura cúbica de face centrada, a alumina A50, além do óxido de alumínio, $\mathrm{Al}_{2} \mathrm{O}_{3}$, de estrutura romboédrica, apresenta a gibbsita, $\mathrm{Al}(\mathrm{OH})_{3}$, de estrutura monoclínica, com as linhas de maior intensidade.

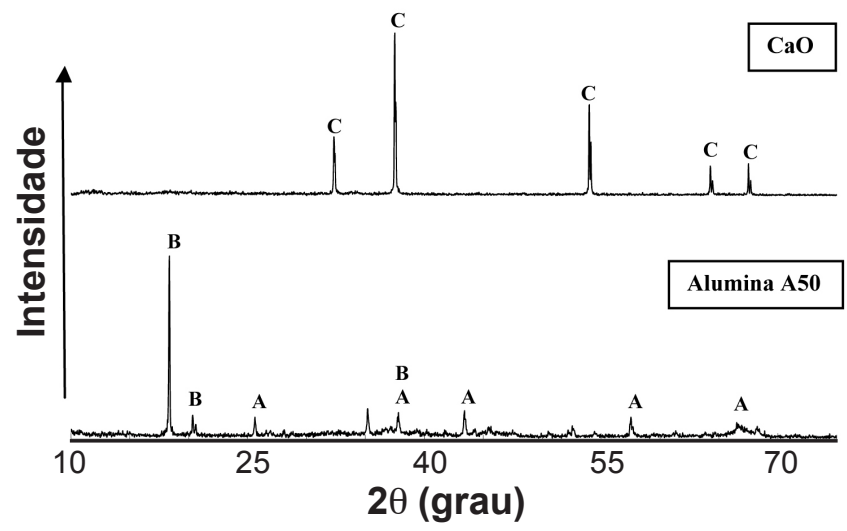

Figura 1: Difratogramas de raios $\mathrm{X}$ da cálcia e da alumina A50. A $-\mathrm{Al}_{2} \mathrm{O}_{3} ; \mathrm{B}-\mathrm{Al}(\mathrm{OH})_{3} ; \mathrm{C}-\mathrm{CaO}$.

[Figure 1: X-ray diffraction patterns of calcia and A50-alumina.]

Baseando-se nos resultados de difração de raios $\mathrm{X}$, verificou-se que a A50 apresenta em sua composição um considerável teor de hidróxido de alumínio. Sendo assim, foi feita uma análise por ATG e DSC em uma amostra do lote utilizado nas sínteses. A Fig. 2 mostra que o teor de resíduos e impurezas que se perdem até os $1448{ }^{\circ} \mathrm{C}$ é de aproximadamente $17 \%$, acima do valor fornecido pelo fabricante, $9,76 \%$ até $1000{ }^{\circ} \mathrm{C}$, mostrando a importância desta caracterização. Destes dados, deduziu-se o fator de correção para o cálculo da massa de alumina na formulação dos cimentos, $83,15 \%$.

$\mathrm{Na}$ curva de DSC pode-se observar que a A50 exibe basicamente cinco picos endotérmicos a 100, 300, 510, 600 e um acima de $1200{ }^{\circ} \mathrm{C}$. Os dois primeiros podem ser correlacionados à perda de água fisicamente adsorvida e a remoção de água de cristalização de hidróxidos. Os três outros picos podem ser atribuídos aos processos de transformação das aluminas de transição que ocorrem durante o tratamento térmico. Pode-se correlacionar a grande perda de massa entre 210 e $320^{\circ} \mathrm{C}$, aproximadamente, à decomposição da gibsita. Durante esse processo ocorre a liberação de vapor de água e a formação de uma alumina de transição, que por sua vez decompõe-se entre $400{ }^{\circ} \mathrm{C}$ e $500{ }^{\circ} \mathrm{C}$. Com o aumento

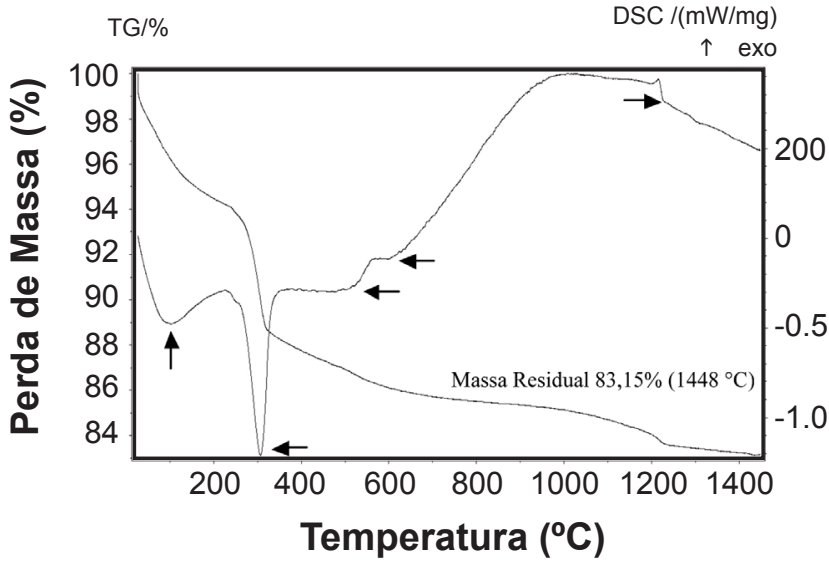

Figura 2: Curvas de ATG e DSC da alumina A50, como recebida. [Figure 2: TG and DSC curves of the A50-alumina.]

da temperatura, acima de $1200{ }^{\circ} \mathrm{C}$, as diversas estruturas cristalinas tendem a se transformarem na mais estável, até a fase $\alpha[10]$.

\section{Etapa sonoquímica}

A Fig. 3 mostra dois difratogramas de raios $\mathrm{X}$ relativos às amostras com composições iniciais centradas nas fases $\mathrm{CA}$ e $\mathrm{CA}_{2}$, submetidas ao processo sonoquímico, secas em estufa a $110^{\circ} \mathrm{C}$ e que não passaram por tratamento térmico. As amostras apresentaram como principais constituintes a alumina $\left(\mathrm{Al}_{2} \mathrm{O}_{3}\right)$, o hidróxido de alumínio $\left(\mathrm{Al}(\mathrm{OH})_{3}\right)$ e um hidrato de cálcio e alumínio o $\mathrm{C}_{3} \mathrm{AH}_{6}\left(3 \mathrm{CaO} \cdot \mathrm{Al}_{2} \mathrm{O}_{3} \cdot 6 \mathrm{H}_{2} \mathrm{O}\right)$. Para a amostra centrada em $\mathrm{CA}$ as linhas de maior intensidade pertencem ao $\mathrm{C}_{3} \mathrm{AH}_{6}$, enquanto que para a amostra centrada em $\mathrm{CA}_{2}$ a formação do hidróxido de alumínio foi favorecida. É surpreendente que não se observe mais qualquer sinal de $\mathrm{CaO}$, significando que sua presença se reduziu a níveis bem baixos $(<3-5 \%$-peso) ou que realmente foi totalmente

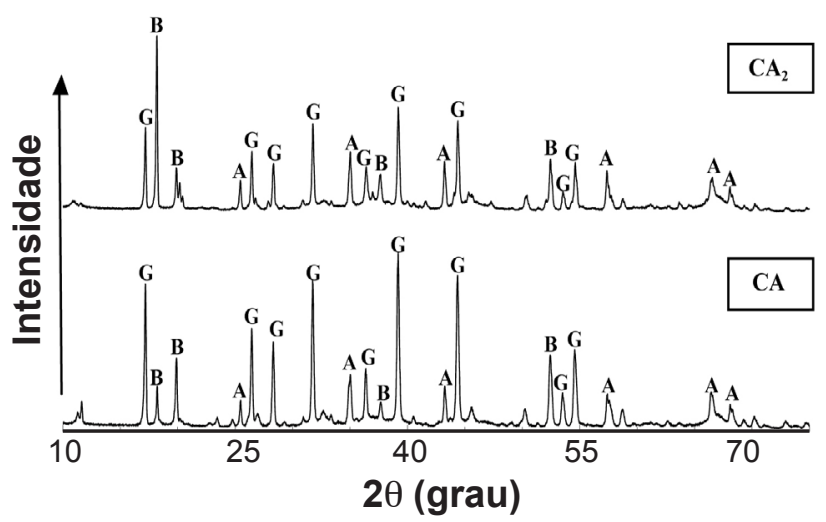

Figura 3: Difratogramas de raios $\mathrm{X}$ das amostras com composições iniciais centradas nas fases $\mathrm{CA}$ e $\mathrm{CA}_{2}$ que passaram pelo processo sonoquímico, foram secadas a $110{ }^{\circ} \mathrm{C}$, mas não sofreram tratamento térmico. $\mathrm{A}-\mathrm{Al}_{2} \mathrm{O}_{3} ; \mathrm{B}-\mathrm{Al}(\mathrm{OH})_{3} ; \mathrm{G}-\mathrm{C}_{3} \mathrm{AH}_{6}$.

[Figure 3: X-ray diffraction patterns of the samples, which the initial composition was centered in the phases $C A$ and $C A_{2}$. These samples were submitted to the sonochemical process dried at $110{ }^{\circ} \mathrm{C}$ and without heat treatment.] 


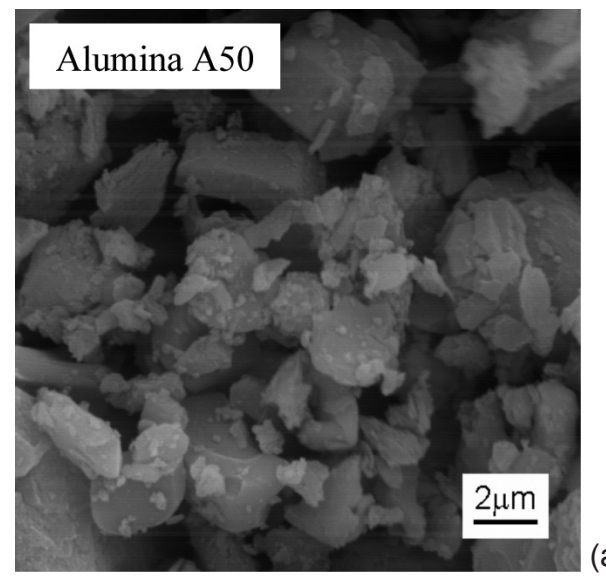

(a)

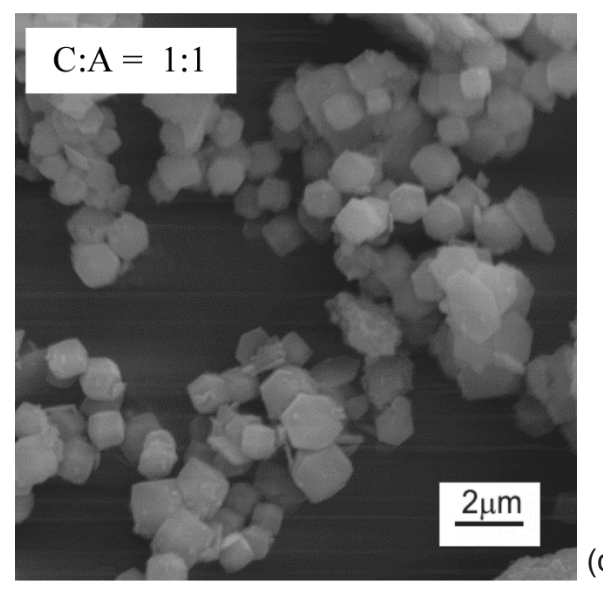

(c)

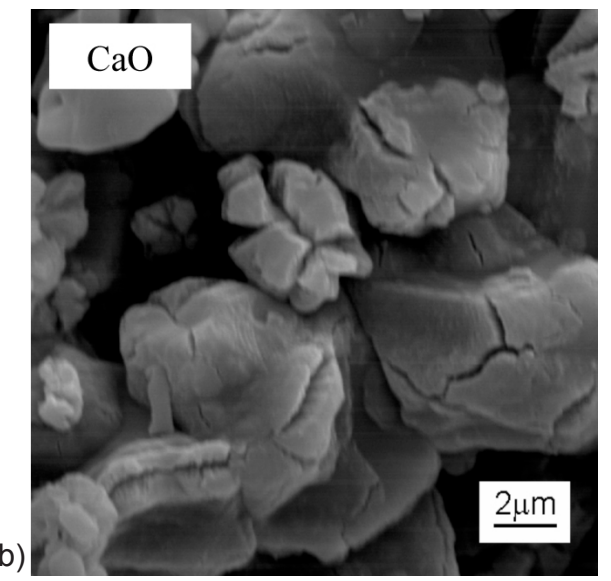

(d)

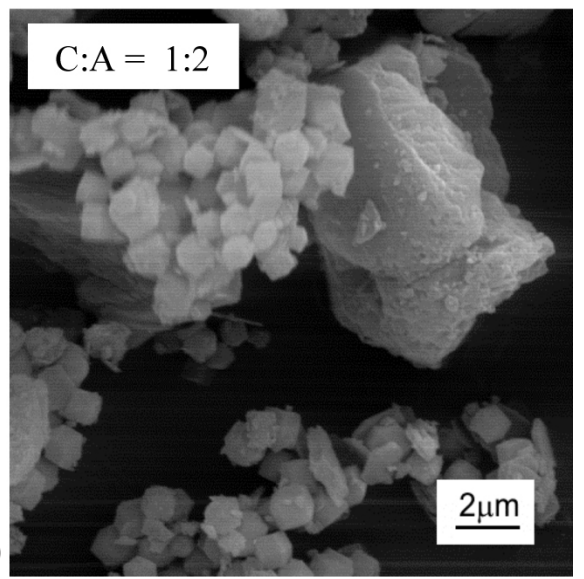

Figura 4: Micrografias de microscopia eletrônica de varredura (a) alumina A50; (b) cálcia; (c) e (d) amostras em que a composição inicial em termos de cálcia:alumina foi de 1:1 e 1:2, respectivamente. Os materiais das figuras (c) e (d) passaram pelo processo sonoquímico, foram secos a $110{ }^{\circ} \mathrm{C}$ e não foram tratados termicamente.

[Figure 4: SEM micrographs: (a) A50-alumina; (b) calcia; (c) and (d), samples with initial molar compositions calcia:alumina of 1:1 and $1: 2$, respectively. The materials of the pictures $(c)$ and $(d)$ were submitted to the sonochemical process, dried at $110{ }^{\circ} \mathrm{C}$ and were not heat treated.]

consumido para a formação do aluminato tricálcico hidratado, que aparece em alta concentração.

Com o objetivo de se comparar as características morfológicas, a cálcia, a alumina e as amostras submetidas ao ultra-som, sem tratamento térmico, foram examinadas no microscópio eletrônico de varredura, Fig. 4.

Observa-se que para ambas as amostras, que passaram pelo ultra-som, os aspectos morfológicos são bem diferentes daqueles apresentados pela cálcia e pela alumina iniciais. Os aglomerados de alumina A50 apresentam uma ampla variedade de tamanho e forma, enquanto que os do $\mathrm{CaO}$ são maiores, mais arredondadas e bastante trincadas. Após o tratamento sonoquímico, uma grande redução no tamanho das partículas pode ser observada. As mudanças morfológicas que ocorreram nestas amostras estão relacionadas à formação dos compostos $\mathrm{C}_{3} \mathrm{AH}_{6}$ pela ação do ultra-som e presença de água. Portanto, o ultra-som além de provocar um forte afinamento no tamanho das partículas parece incentivar a formação do composto hidratado. Na Fig. 4d observa-se claramente uma partícula original fraturada pela ação do ultra-som.

\section{Etapa do tratamento térmico}

Foram preparadas duas amostras de cada composição inicial correspondente às fases $\mathrm{CA}$ e $\mathrm{CA}_{2}$. Uma amostra passou pelo processo sonoquímico e a outra não. Todas as quatro amostras foram tratadas termicamente nas mesmas condições de $1000^{\circ} \mathrm{C}$ por $1 \mathrm{~h}$. Após o tratamento térmico foi possível observar uma mudança na coloração, de cinza para branca em todas elas.

A Fig. 5 apresenta os difratogramas de raios $\mathrm{X}$ das amostras com proporção molar de cálcia e alumina de 1:1, em que os difratogramas (a) e (b) representam, respectivamente, a amostra submetida ao banho de ultra-som e a que não foi exposta às ondas ultra-sônicas.

Comparando-se os difratogramas das amostras com e sem exposição ao ultra-som, pode-se observar uma forte mudança nas linhas de difração. Na Fig. 5a as linhas de maior intensidade caracterizam a fase $\mathrm{C}_{12} \mathrm{~A}_{7}$. Para a amostra que não foi submetida ao tratamento sonoquímico, Fig. 5b, a linha de maior intensidade corresponde à cálcia, um dos reagentes de partida. Em ambas amostras também aparecem 

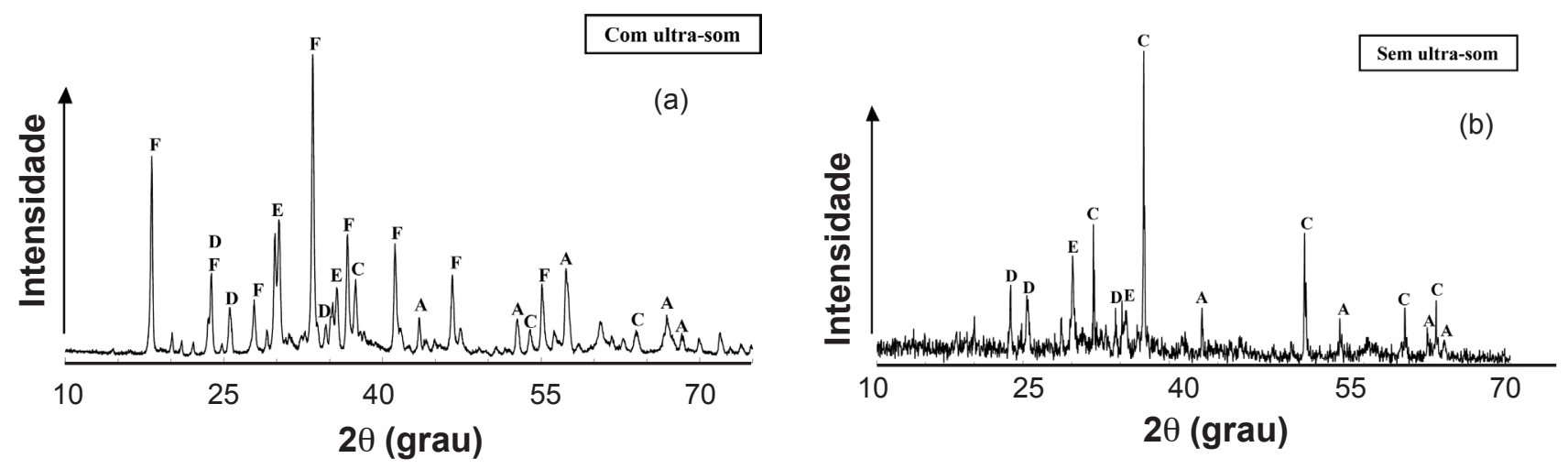

Figura 5: Difratogramas de raios X das amostras com composição molar de cálcia:alumina de 1:1: (a) com aplicação do ultra-som e (b) sem aplicação do ultra-som. Ambas as amostras sofreram tratamento térmico a $1000{ }^{\circ} \mathrm{C}$ durante $1 \mathrm{~h}$. Legenda: $\mathrm{A}-\mathrm{Al}_{2} \mathrm{O}_{3} ; \mathrm{C}-\mathrm{CaO} ; \mathrm{D}-\mathrm{CA}$; $\quad \mathrm{E}$ $-\mathrm{CA} ; \mathrm{F}-\mathrm{C}_{12} \mathrm{~A}_{7}$.

[Figure 5: X-ray diffraction patterns of the samples, which molar compositions calcia:alumina is 1:1: (a) submitted to ultrasound and (b) no ultrasound. Both samples were heat treated at $1000^{\circ} \mathrm{C}$ for $\left.1 \mathrm{~h}.\right]$
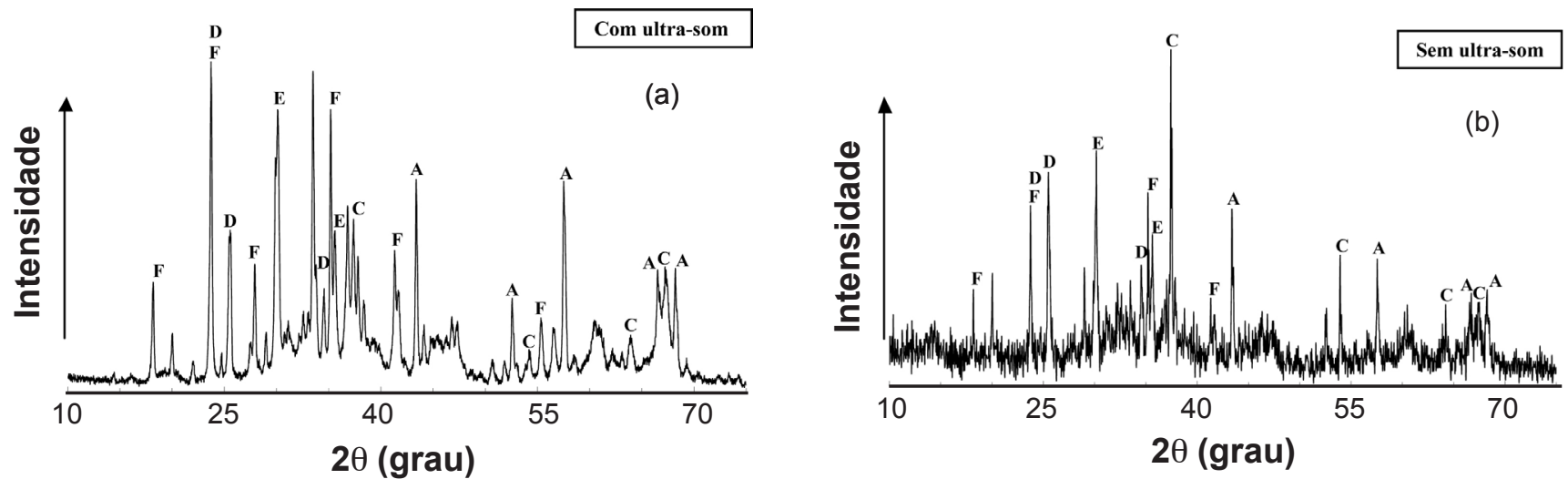

Figura 6: Difratogramas de raios X das amostras com composição molar inicial de cálcia:alumina de 1:2: (a) com aplicação do ultra-som e (b) sem aplicação do ultra-som. Ambas as amostras sofreram tratamento térmico a $1000{ }^{\circ} \mathrm{C}$ durante $1 \mathrm{~h}$. Legenda: $\mathrm{A}-\mathrm{Al}_{2} \mathrm{O}_{3} ; \mathrm{C}-\mathrm{CaO} ; \mathrm{D}-\mathrm{CA} ; \mathrm{E}$ $-\mathrm{CA} ; \mathrm{F}-\mathrm{C}_{12} \mathrm{~A}_{7}$

[Figure 6: X-ray diffraction patterns of the samples, which molar compositions calcia:alumina is 1:2: (a) submitted to ultrasound and (b) no ultrasound. Both samples were heat treated at $1000^{\circ} \mathrm{C}$ for $\left.1 \mathrm{~h}.\right]$

com intensidades mais baixas linhas características do $\mathrm{Al}_{2} \mathrm{O}_{3}$ e de outras fases do sistema cálcia-alumina, $\mathrm{CA}_{\text {e }} \mathrm{CA}_{2}$. Essa comparação mostra que apesar de um tratamento térmico de apenas $1000{ }^{\circ} \mathrm{C}$ durante $1 \mathrm{~h}$, a ação do ultra-som foi fundamental para a efetivação da reação entre as matériasprimas. Notar na Fig. 5a como as linhas do produto-alvo, CA, já aparecem claramente.

A Fig. 6 apresenta os difratogramas das amostras com proporção inicial de cálcia e alumina de 1:2. Para a amostra submetida às ondas ultra-sônicas, Fig. 6a, os picos de maior intensidade caracterizam as fases do sistema cálcia-alumina $\mathrm{CA}_{2}, \mathrm{CA}$ e $\mathrm{C}_{12} \mathrm{~A}_{7}$, enquanto que, para a amostra que não foi submetida ao processo sonoquímico, Fig. $6 \mathrm{~b}$, o pico de maior intensidade corresponde, novamente, à cálcia. Comparando-se os difratogramas (b) das Figs. 5 e 6, pode-se observar que para a amostra com composição molar inicial cálcia:alumina de 1:2, as linhas característica das fases do sistema binário cálcia-alumina aparecem com intensidades mais significativas do que na amostra em que a composição inicial foi de 1:1.
Embora não quantitativos, os difratogramas das Figs. 5 e 6 parecem indicar que para as amostras expostas às ondas ultra-sônicas, a cálcia inicial foi bastante consumida. Fases ricas em cálcio são formadas quando se aplica a etapa sonoquímica e as linhas características das matérias-primas iniciais aparecem com intensidades relativas mais baixas. Diferentemente, as amostras que não foram expostas às ondas ultra-sônicas têm as linhas do $\mathrm{CaO}$ como as mais intensas. Sendo assim, pode-se concluir, previamente, que a aplicação do ultra-som foi, evidentemente, necessária para aumentar a eficiência da reação desejada.

Vale notar que no sistema estudado, o ultra-som provocou o aparecimento do $\mathrm{C}_{12} \mathrm{~A}_{7}$, em quantidades importantes mesmo para misturas mais ricas em $\mathrm{Al}_{2} \mathrm{O}_{3}$ como é o caso da proporção 1:2 de $\mathrm{CaO}: \mathrm{Al}_{2} \mathrm{O}_{3}$. Isso indica que a formação da fase $\mathrm{C}_{12} \mathrm{~A}_{7}$ é mais propícia que a formação das outras, $\mathrm{CA}$ e $\mathrm{CA}_{2}$, em $1000{ }^{\circ} \mathrm{C}$ por $1 \mathrm{~h}$. Essa situação pode ser explicada pela ação do ultra-som e a presença de água, além disso, esta fase é a mais favorável de ser formada [1]. Como mostrado na Fig. 3, após o processo sonoquímico ocorre 
a formação do aluminato tricálcico hidratado, $\mathrm{C}_{3} \mathrm{AH}_{6} \cdot \mathrm{Na}$ etapa de tratamento térmico, mudanças mineralógicas de fases ocorrem devido ao processo de desidratação e o $\mathrm{C}_{12} \mathrm{~A}_{7}$ é a primeira a ser formada a partir desse hidrato. Com o aumento da temperatura e/ou do tempo de reação, esta fase mais rica em $\mathrm{CaO}$ tende a se converter nas outras fases do sistema cálcia-alumina, dependendo da oferta e reatividade da alumina $[5,11]$.

\section{Influência das condições de tratamento térmico}

Baseando-se nos resultados de difração de raios $\mathrm{X}$ das amostras com e sem exposição ao ultra-som e tratadas termicamente a $1000{ }^{\circ} \mathrm{C}$ por $1 \mathrm{~h}$, Figs. 5 e 6 , verificou-se a ação positiva das ondas ultra-sônicas no aparecimento das fases do sistema binário cálcia-alumina. Considerando-se que as ondas ultra-sônicas aumentam a eficiência da reação entre a cálcia e a alumina, estudou-se o efeito da temperatura e do tempo de tratamento térmico no aparecimento das fases.

A Fig. 7 apresenta os difratogramas das amostras com proporção molar de cálcia e alumina de 1:1 obtidas em diferentes temperaturas de tratamento térmico com duração de 1 h, Fig. 7a, e 6 h, Fig. 7b. Pode-se observar a evolução das fases devido às diferentes condições de tratamento térmico. A amostra tratada a $1000{ }^{\circ} \mathrm{C}$ é formada predominantemente pela fase $\mathrm{C}_{12} \mathrm{~A}_{7}$ apresentando também picos característicos das fases $\mathrm{CA}^{\prime} \mathrm{CA}_{2} \mathrm{em}$ menores proporções e baixos picos da alumina e da cálcia. Nesta mesma temperatura, o aumento para $6 \mathrm{~h}$ no tempo de tratamento não teve uma influencia significante no aparecimento das fases. Com o aumento da temperatura, entretanto, pode-se observar que as intensidades das linhas do $\mathrm{C}_{12} \mathrm{~A}_{7}$ diminuem consideravelmente, enquanto ocorre um aumento nas intensidades das linhas da fase de interesse o CA. A $1200{ }^{\circ} \mathrm{C}$ também aparecem linhas característica
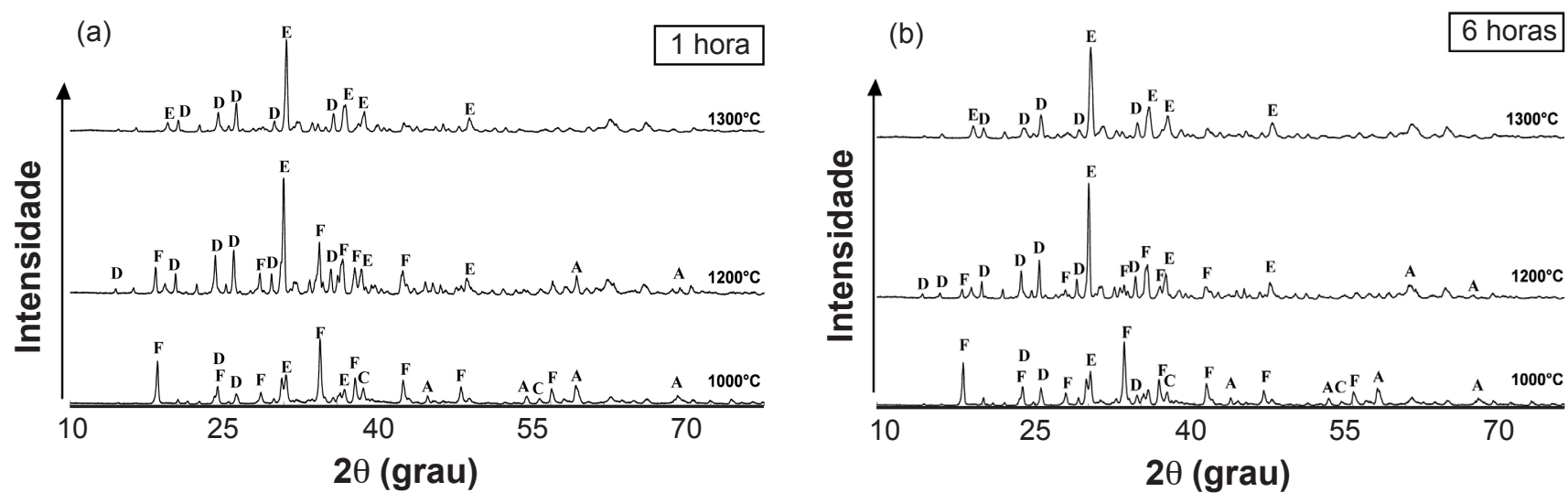

Figura 7: Difratogramas de raios $\mathrm{X}$ das amostras com composição molar inicial de cálcia:alumina de 1:1 submetidas ao processo sonoquímico e em três diferentes temperaturas de tratamento térmico, durante $1 \mathrm{~h}$ (a) e $6 \mathrm{~h}$ (b). Legenda: $\mathrm{A}-\mathrm{Al}_{2} \mathrm{O}_{3} ; \mathrm{C}-\mathrm{CaO} ; \mathrm{D}-\mathrm{CA} ; \mathrm{E}-\mathrm{CA} ; \mathrm{F}-\mathrm{C}_{12} \mathrm{~A}_{7}$ [Figure 7: X-ray diffraction patterns of the samples, which molar compositions calcia:alumina is 1:1, submitted to ultrasound and thermally treated at three different temperatures, for $1 \mathrm{~h}(\mathrm{a})$ and $6 \mathrm{~h}(\mathrm{~b}) . \mathrm{J}$
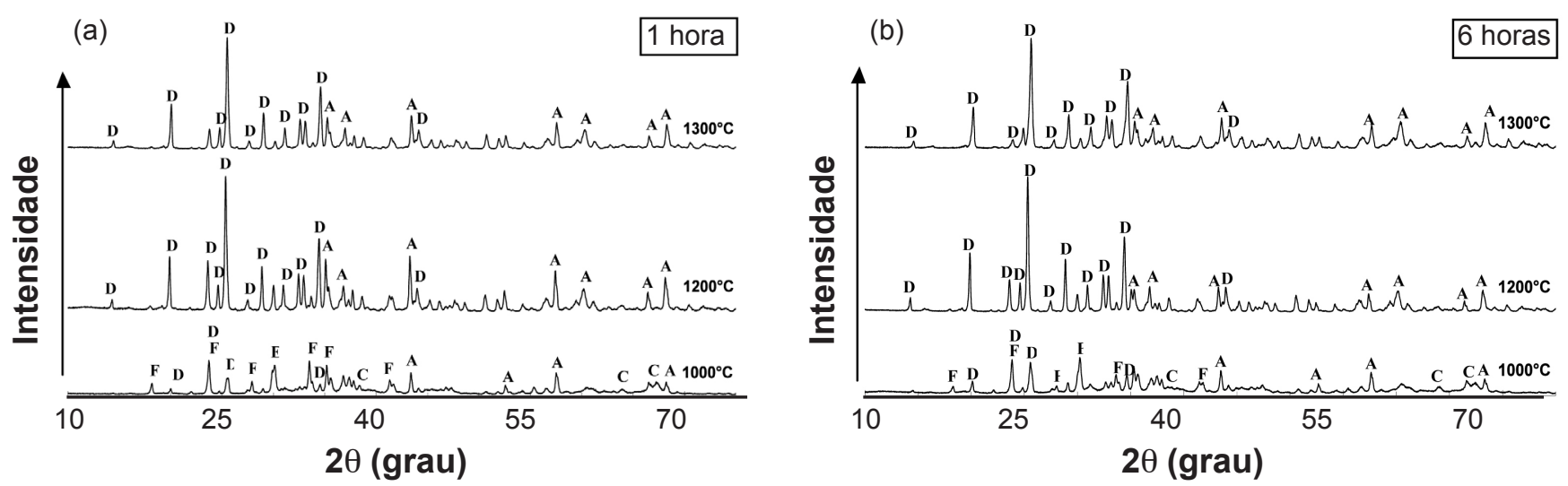

Figura 8: Difratogramas de raios X das amostras com proporção molar inicial de cálcia:alumina de 1:2, submetidas ao processo sonoquímico e em diferentes temperaturas de tratamento térmico, durante $1 \mathrm{~h}$ (a) e $6 \mathrm{~h}$ (b). Legenda: $\mathrm{A}-\mathrm{Al}_{2} \mathrm{O}_{3} ; \mathrm{C}-\mathrm{CaO} ; \mathrm{D}-\mathrm{CA} ; \mathrm{E}-\mathrm{CA} ; \mathrm{F}-\mathrm{C}_{12} \mathrm{~A}_{7}$. [Figure 8: X-ray diffraction of patterns the samples, which molar compositions calcia:alumina is 1:2, submitted to ultrasound and thermally treated at three different temperatures, for $1 \mathrm{~h}(a)$ and $6 \mathrm{~h}(\mathrm{~b})$.] 
da fase $\mathrm{CA}_{2}$. Em $1300{ }^{\circ} \mathrm{C}$, a fase $\mathrm{C}_{12} \mathrm{~A}_{7}$ foi totalmente convertida nas fases $\mathrm{CA}$ e $\mathrm{CA}_{2}$, com o predomínio de $\mathrm{CA}$. Novamente, o aumento do tempo de tratamento térmico, de 1 para $6 \mathrm{~h}$, não teve efeito significativo, mostrando que apenas $1 \mathrm{~h}$ seria suficiente para ocorrer as reações; porém, nota-se que a conversão do $\mathrm{C}_{12} \mathrm{~A}_{7} \mathrm{em}$ outras fases é mais efetiva já a $1200{ }^{\circ} \mathrm{C}$ para $6 \mathrm{~h}$ de tratamento do que para apenas $1 \mathrm{~h}$.

A Fig. 8 mostra os difratogramas de raios $\mathrm{X}$ das amostras com proporção molar de cálcia e alumina de 1:2 e tratadas termicamente a 1000,1200 e $1300{ }^{\circ} \mathrm{C}$, durante $1 \mathrm{~h}$, Fig. 8a, e 6 h, Fig. 8b. A composição termicamente tratada a $1000{ }^{\circ} \mathrm{C}$ apresentou como principais fases cristalinas os constituintes do cimento, $\mathrm{CA}, \mathrm{CA}_{2}$ e $\mathrm{C}_{12} \mathrm{~A}_{7}$, juntamente com $\mathrm{Al}_{2} \mathrm{O}_{3}$ e $\mathrm{CaO}$. Com o aumento da temperatura para 1200 ${ }^{\circ} \mathrm{C}$ e para $1300{ }^{\circ} \mathrm{C}$, observa-se um aumento significativo da intensidade dos picos da fase-alvo, o $\mathrm{CA}_{2}$, enquanto que os picos da fase $\mathrm{C}_{12} \mathrm{~A}_{7}$ desaparecem. Nestas amostras, também aparecem linhas características da alumina. Podese observar que para uma mesma temperatura, o aumento na duração do tratamento térmico de uma para seis horas não apresentou mudanças significativas na composição de fases do material final. Comparada com a Fig. 7, a Fig. 8 mostra que a proporção relativa inicial de $\mathrm{C}_{12} \mathrm{~A}_{7}$ para a temperatura de $1000{ }^{\circ} \mathrm{C}$ é menor no material centrado em $\mathrm{CA}_{2}$ do que em CA, já que para aquela, a composição se afasta mais do equilíbrio da fase $\mathrm{C}_{12} \mathrm{~A}_{7}$.

A partir dos difratogramas das Figs. 7 e 8 observa-se a complexidade do processo de desenvolvimento de fases nesses materiais. A $1000{ }^{\circ} \mathrm{C}$ verifica-se a formação de diversas fases do sistema cálcia-alumina e com um aumento de $200^{\circ} \mathrm{C}$ na temperatura, a fase alvo já tem seu aparecimento favorecido.

A morfologia das partículas das amostras de ambas as composições, $\mathrm{CA}$ e $\mathrm{CA}_{2}$, tratadas termicamente a $1000{ }^{\circ} \mathrm{C}$, $1200{ }^{\circ} \mathrm{C}$ e $1300{ }^{\circ} \mathrm{C}$, durante $1 \mathrm{~h}$, estão apresentadas na Fig. 9. É fundamental notar nas fotos de microscopia eletrônica de varredura que após o tratamento térmico as partículas possuem morfologia diferente daquela apresentada pelas amostras antes do tratamento térmico, Fig. 4. Estas mudanças morfológicas estão associadas à formação das diversas fases de aluminato de cálcio que ocorre em função

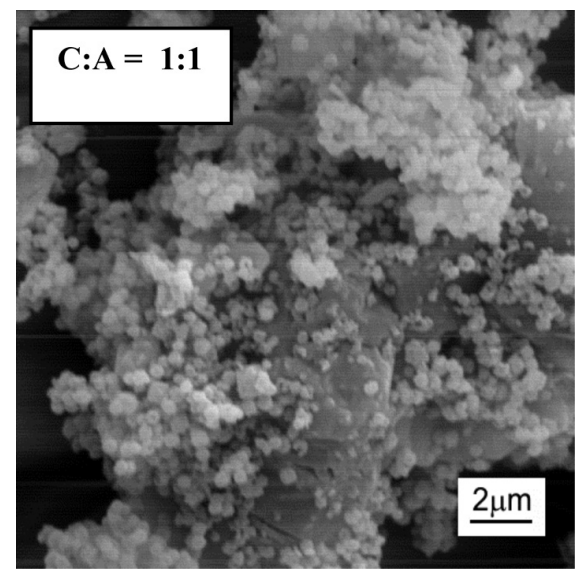

(a)

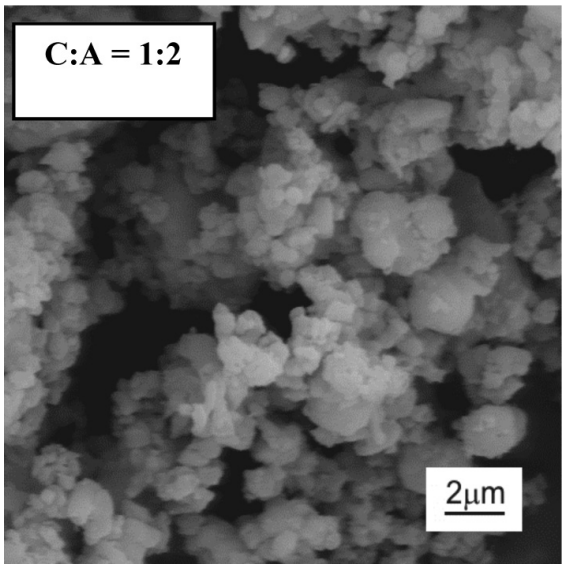

(d)

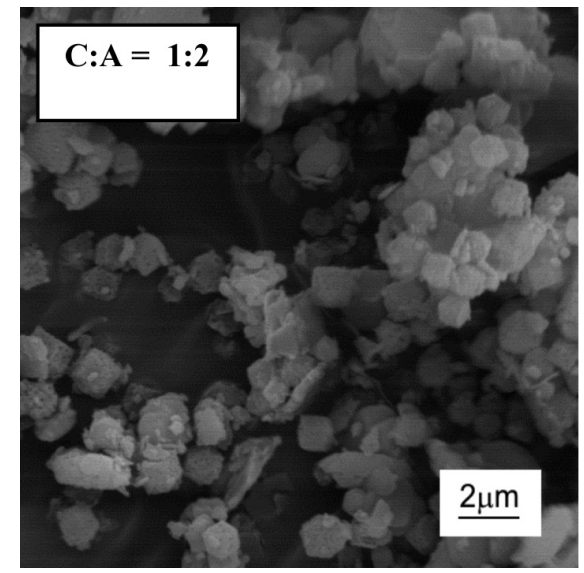

(b)

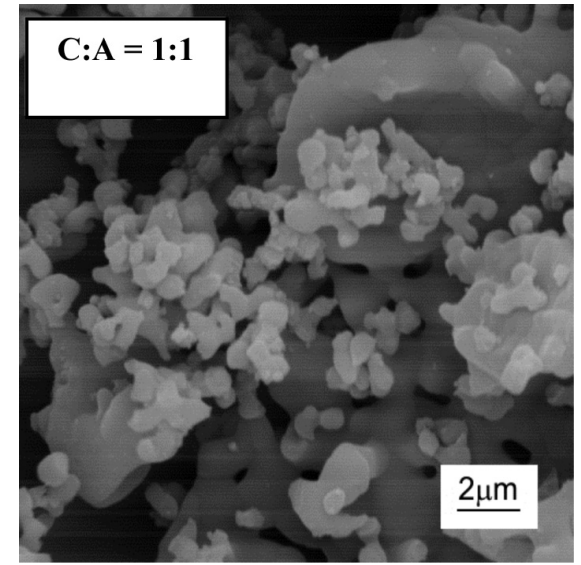

(e)

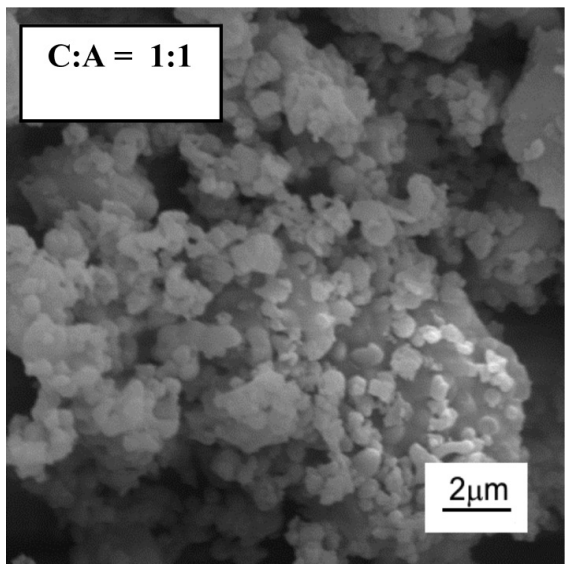

(c)

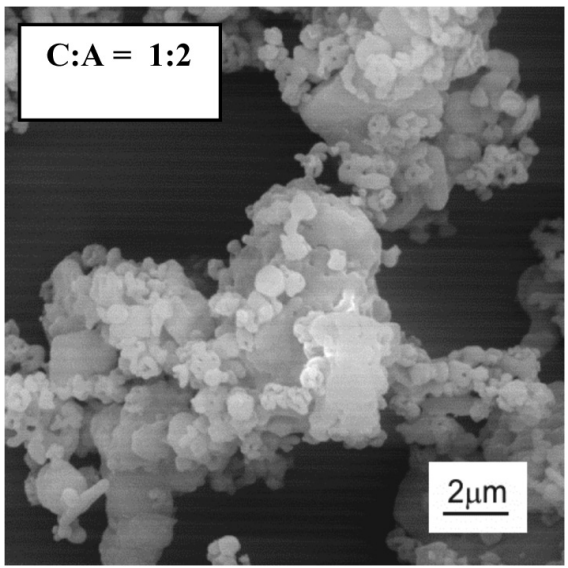

(f)

Figura 9: Micrografias obtidas por microscopia eletrônica de varredura das amostras com composições iniciais na proporção de cálcia:alumina de 1:1, (a), (c) e (e) e 1:2, (b), (d) e (f). As amostras foram tratadas termicamente durante $1 \mathrm{~h}$.

[Figure 9: SEM micrographs of the samples with initial compositions calcia:alumina of $1: 1(a),(c)$ and $(e)$ and $1: 2,(b),(d)$ and $(f)$. The samples were heat treated for $1 \mathrm{~h}$. 
da temperatura. Essas micrografias revelam os diferentes tamanhos das partículas. Algumas são maiores com formato irregular enquanto que um particulado mais fino, em escala nanométrica, se apresenta em regiões de aglomeração. Do tratamento térmico de $1300{ }^{\circ} \mathrm{C}$ (Figs. 9e e 9f), observa-se a formação de pescoços, semelhantemente ao que ocorre no início da sinterização, sugerindo a coalescência das partículas. Este processo pode ser observado em ambas às composições, $\mathrm{CA}$ e $\mathrm{CA}_{2}$, mas para a amostra $\mathrm{CA}$ este efeito é mais evidente. Observa-se também, nesta amostra, a presença de partículas maiores com morfologia semelhante à morfologia de algumas partículas presentes na amostra de mesma composição tratadas a $1000{ }^{\circ} \mathrm{C}$.

Foi também caracterizada a resistência mecânica desenvolvida por estes materiais, empregando-se o ensaio de compressão diametral. As fases hidráulicas formadas quando os cimentos aluminosos são misturados com água são as responsáveis pelo desenvolvimento da resistência mecânica do material verde. O tipo e as proporções dos diferentes hidratos que podem ser formados durante o processo de hidratação é fortemente dependente da composição mineralógica do cimento, da relação água:cimento e principalmente da temperatura de cura [12]. Como estas duas últimas variáveis foram controladas durante o experimento, as diferenças apresentadas nos valores de resistência mecânica podem ser atribuídas principalmente à diversificada composição de fases que os materiais preparados pelo processo sonoquímico apresentam após os diferentes tratamentos térmicos.

A Fig. 10 permite comparar a resistência mecânica das pastas preparadas com $50 \%$ de alumina (A1000) e $50 \%$ de cimento sintetizado nas variadas condições de

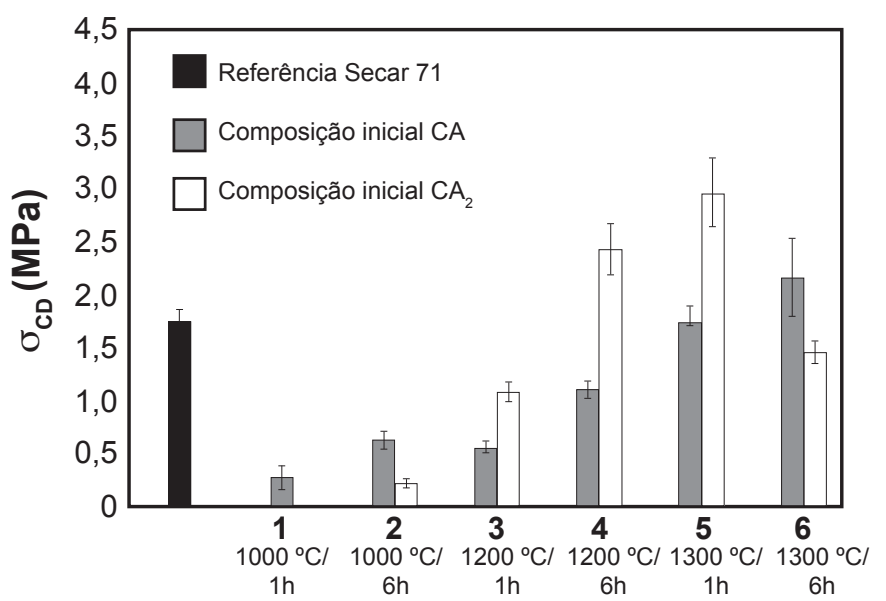

Figura 10: Resistência à compressão diametral das pastas de cimento e alumina, utilizando-se como cimento o material preparado pelo processo sonoquímico, nas diversas condições de tratamento térmico e um cimento de aluminato de cálcio comercial como referência.

[Figure 10: Splitting tensile strength of pastes consisting of cement and alumina, using the calcium aluminates prepared through the sonochemical process, in different thermal treatment conditions and commercial cement as reference.] tratamento térmico. A resistência mecânica desenvolvida pelos materiais preparados pelo processo sonoquímico foi comparada à resistência de um material preparado com um cimento de aluminato de cálcio comercial. A resistência à compressão diametral do material preparado com aluminato de cálcio comercial, após a secagem, foi de 1,75 MPa. Observa-se um aumento gradativo no valor da resistência mecânica dos corpos de provas conforme se aumenta a temperatura e o tempo de tratamento térmico utilizados na síntese dos aluminatos de cálcio. A baixa resistência mecânica apresentada pelos materiais 1,2, 3 e 4 (ver eixo das abscissas na Fig. 10) no caso do cimento centrado na fase $\mathrm{CA}$, pode estar relacionada à presença da fase $\mathrm{C}_{12} \mathrm{~A}_{7}$. Esta fase se hidrata e endurece rapidamente comprometendo a hidratação das outras fases o que implica na perda de resistência mecânica dos corpos de prova. Os corpos de prova preparados com o material centrado na fase $\mathrm{CA}_{2}$ apresentaram maior resistência mecânica que os preparados com o material centrado na fase $\mathrm{CA}$ a partir do tratamento térmico de $1200{ }^{\circ} \mathrm{C}$ durante $1 \mathrm{~h}$, exceto para a amostra tratada termicamente em $1300{ }^{\circ} \mathrm{C}$ por $6 \mathrm{~h}(1,46$ $\mathrm{MPa}$ ). Não foi possível medir a resistência mecânica dos corpos de prova preparados com o material centrado na fase $\mathrm{CA}_{2}$ e tratados termicamente a $1000{ }^{\circ} \mathrm{C}$ durante $1 \mathrm{~h}$, pois após a sua secagem houve uma significativa retração dos corpos e estes perderam a forma cilíndrica. Estas retrações podem ser associadas às conversões de fases que ocorrem nos hidratos durante a cura. Destaca-se a elevada resistência à compressão diametral desenvolvida pelos corpos de prova com os materiais 5 e 6 preparados com o material centrado na fase $\mathrm{CA}$, com valores semelhantes aos do material preparado com o aluminato de cálcio comercial, utilizado como referencia. O material 5, preparado com o cimento centrado na fase $\mathrm{CA}_{2}$, dentre todos os materiais, foi o que apresentou a maior resistência mecânica, $2,96 \mathrm{MPa}$, inclusive bastante superior à resistência do material preparado com o cimento de referência.

Embora a análise de difração de raios $\mathrm{X}$ de alguns materiais não indique diferenças significativas em termos de composição de fases, as diferenças nos valores de resistência mecânica podem estar relacionadas com os teores relativos das fases presentes. Desta maneira, foi feita uma análise semiquantitativa de fases, empregando-se o método de Rietveld, como auxílio na interpretação destes resultados. Como os materiais inicialmente centrados em $\mathrm{CA}_{2}$ apresentaramse superiores em relação ao cimento comercial, iniciou-se a quantificação das fases com estes materiais. Na Fig. 11 podem-se observar os valores obtidos no ensaio mecânico (eixo das ordenadas da direita) e relacioná-los com a concentração de $\mathrm{CA}_{2}$ e alumina presente em cada material (eixo das ordenadas da esquerda). Apesar dos difratogramas de raios $\mathrm{X}$ destas amostras (Fig. 8) também apresentarem outras fases, a semi-quantificação foi feita para as fases dominantes $\mathrm{CA}_{2}$ e $\mathrm{Al}_{2} \mathrm{O}_{3}(\mathrm{~A})$.

Pode-se observar que o aumento na resistência à compressão diametral é acompanhado pelo aumento no teor da fase $\mathrm{CA}_{2}$ e pela redução no de $\mathrm{Al}_{2} \mathrm{O}_{3}$. Este resultado é 


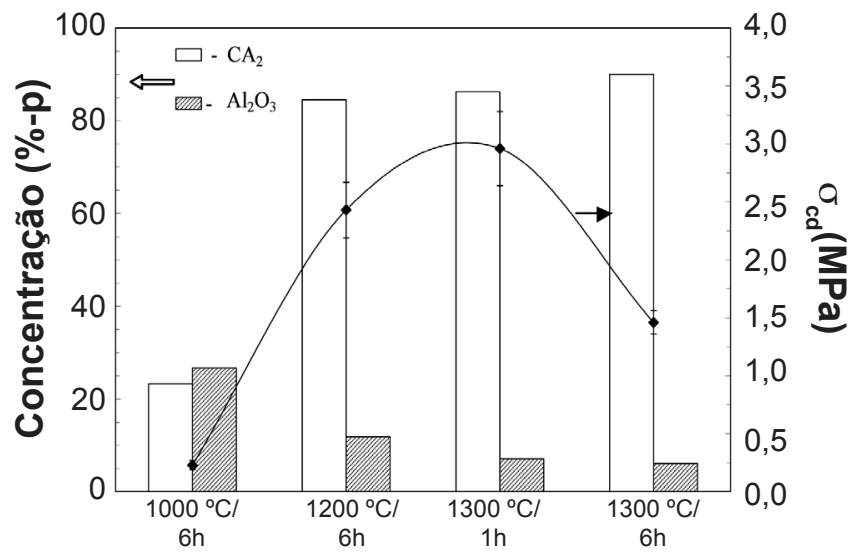

Figura 11: Valores obtidos no ensaio de resistência à compressão diametral (escala da direita) das pastas com composição inicial $\mathrm{CA}_{2}$, em relação à quantidade das fases $\mathrm{CA}_{2}$ e $\mathrm{Al}_{2} \mathrm{O}_{3}(\mathrm{~A})$ (escala da esquerda).

[Figure 11: Splitting tensile strength (vertical scale of the right) of pastes, which the initial composition is $\mathrm{CA}_{2}$, and the concentration of the phases $\mathrm{CA}_{2}$ and $\mathrm{Al}_{2} \mathrm{O}_{3}$ (vertical scale of the left).]

coerente com o reportado, que prevê a formação da fase $\mathrm{CA}_{2}$ e o consumo de alumina com o aumento da temperatura e/ ou tempo de tratamento térmico [1]. Porém, não há correlação entre $\sigma_{\mathrm{CD}}$ e a concentração das fases mostradas. Inicialmente, pode-se atribuir a melhora na resistência mecânica destes materiais ao aumento na concentração do $\mathrm{CA}_{2}$. Contudo, algumas considerações devem ser feitas. Observa-se um aumento de resistência desproporcional ao aumento da concentração da fase $\mathrm{CA}_{2}$ e ainda há o comportamento diferente do material preparado a $1300{ }^{\circ} \mathrm{C}$ durante $6 \mathrm{~h}$. A melhora na resistência mecânica destes materiais, inicialmente, pode ser atribuída ao aumento na concentração do $\mathrm{CA}_{2}$. Contudo, algumas considerações devem ser feitas. Observase um aumento de resistência desproporcional ao aumento da concentração da fase $\mathrm{CA}_{2}$ e ainda há o comportamento diferente do material preparado a $1300{ }^{\circ} \mathrm{C}$ durante $6 \mathrm{~h}$. Sendo assim, pode-se considerar que o desenvolvimento da resistência mecânica não está apenas ligado aos teores das fases presentes. Estas diferenças também podem ser influenciadas pela distribuição granulométrica do material obtido no final do processo e pela presença, em baixas concentrações, de fases de elevada hidraulicidade que não foram detectadas pela difração de raios $X$.

Os estudos continuam no sentido de uma quantificação das fases presentes nos cimentos sintetizados, na busca por um esclarecimento sobre o comportamento mecânico dos materiais refratários obtidos. De qualquer maneira, este trabalho mostra como é promissora a rota aqui estabelecida, via sonoquímica, para a obtenção de materiais de significante importância para os concretos refratários.

\section{CONCLUSÕES}

Observou-se que para uma mesma relação molar entre os reagentes cálcia e alumina, as amostras que foram previamente submetidas ao ultra-som geraram um produto final com composição de fases diferente das amostras não expostas a esta ação. Sendo assim, pode-se considerar que, para as formulações centradas em $\mathrm{CA}_{\text {e }} \mathrm{CA}_{2}$, o processo sonoquímico aumentou efetivamente a reatividade das matérias-primas, principalmente a da cálcia, uma vez que para ambas as proporções empregadas, quando submetidas às ondas ultrasônicas, fases de aluminatos de cálcio mais ricas em cálcio estão presentes em altas concentrações. As condições de tratamento térmico são variáveis importantes na síntese dos aluminatos de cálcio, pois influenciam fortemente o aparecimento das fases pertencentes ao sistema cálcia-alumina. Como resultado, temse que a temperatura é muito mais significativa que o tempo de tratamento, no que diz respeito ao desenvolvimento das fases aluminosas. Pelos difratogramas de raios X observou-se que na temperatura mais baixa de tratamento térmico (1000 ${ }^{\circ} \mathrm{C}$ ), as fases de aluminato de cálcio mais ricas em cálcia estão presentes em altas concentrações. Com a utilização do processo sonoquímico, a fase de interesse começa a aparecer no tratamento térmico já a $1000{ }^{\circ} \mathrm{C}$; contudo, a efetivação da fase alvo ocorre em temperaturas mais elevadas, 1200 e $1300{ }^{\circ} \mathrm{C}$ para as amostras com composição inicial centrada nas fases $\mathrm{CA}_{2}$ e $\mathrm{CA}$, respectivamente. Esta temperatura é, no mínimo, $100{ }^{\circ} \mathrm{C}$ mais baixa do que aquela necessária no processo convencional de fabricação de cimentos refratários de aluminatos de cálcio. Os corpos de prova preparados com os materiais sintetizados pelo processo sonoquímico em que as fases de interesse começam a prevalecer, materiais 5 e 6 no caso do cimento centrado na fase $\mathrm{CA}$ e materiais $4,5 \mathrm{e}$ 6 no caso do cimento centrado na fase $\mathrm{CA}_{2}$, apresentaram boa resistência mecânica. Os diferentes valores obtidos no ensaio de compressão diametral podem ser justificados em parte pelas diferenças de composição de fases dos produtos de síntese. Contudo, há casos em que materiais com a mesma composição de fases apresentaram resistências mecânicas distintas. Sendo assim, pode-se concluir que embora a composição de fases do material seja a maior responsável pela influência no desenvolvimento da resistência mecânica dos corpos de provas, devem existir outros fatores que estariam afetando esse aspecto. Pelas imagens de microscopia eletrônica de varredura também não foi possível observar uma relação entre as mudanças morfológicas que esclarecessem o comportamento mecânico gerado por elas. Os resultados obtidos neste trabalho, embora ainda parciais, mostram que o processo sonoquímico apresenta grande potencial na obtenção de aluminatos de cálcio em temperaturas inferiores àquelas utilizadas pelas rotas convencionais. No entanto, novos estudos ainda devem ser realizados para consolidar o entendimento da influência das ondas ultra-sônicas na preparação destes materiais. Além disso, há a necessidade de uma análise mais detalhada das propriedades desenvolvidas por estes materiais quando em contato com a água, para que se consiga compreender claramente sua influência sobre a resistência mecânica final.

\section{AGRADECIMENTOS}

Ao CNPq pela bolsa de mestrado (Proc. 143525/2008-5), 
pela bolsa de produtividade em pesquisa Procs. 304980/20030, 301073/2006-6 e 304.566/2007-1, e pela bolsa de IC Proc 501555-63. À FAPESP pelo Projeto Temático Proc. 2001/ 04324-8. À Alcoa Alumínio S.A pela doação da matériaprima A50.

\section{REFERÊNCIAS}

[1] T. A. Cüneyt, Chemical Preparation of the Binary Compounds in the Calcia-Alumina System by SelfPropagating Combustion Synthesis, J. Am. Ceram. Soc. 81, 11 (1998) 2853-63.

[2] J. E. Kopanda, G. MacZura, Production Processes, Properties, and Aplication for Calcium Aluminate Cements, in: L. D. Hart, Alumina Chemicals, Science and Technology Handbook, Westerville, OH, EUA (1990) 171-184.

[3] F. M. Lea, The Chemistry of Cement and Concrete, $3^{\text {a }}$ Ed., Edward Arnold Ltd., London, Inglaterra (1970) p. 28$81 ; 177-249 ; 490-527$.

[4] W. E. Lee, W. Vieira, S. G. Zhang, A. H. Sarpoolaky, C. Parr, Castable refractory concretes, Int. Mater. Rev. 46, 3 (2001) 145-167

[5] M. A. Gülgün, O. O. Popoola, W. M. Kriven, Chemical Synthesis and Characterization of Calcium Aluminate
Powders, J. Am. Ceram. Soc. 77, 2 (1994) 531-39.

[6] V. K. Singh, M. M. Ali, U. K. Mandal, Formation Kinetics of Calcium Aluminates. J. Am. Ceram. Soc. 73, 11 (1990) 872-76.

[7] M. A. U. Martines, M. R Davolos, M. Jafelicci Júnior, O Efeito do Ultra-Som em Reações Químicas, Química Nova 23, 2 (2000) 251-156.

[8] A. Gedanken, Using Sonochemistry for the Fabrication of Nanomaterials, J. Ultrasonics Sonochem. 11 (2004), 47 55.

[9] F. A. Rodrigues, Low-Temperature Synthesis of Cements from Rice Hull Ash, Cement Concrete Res. 33, 10, (2003) 1525-1529.

[10] C. R. Oliveira, Efeito da temperatura e de aditivos de secagem na permeabilidade de concretos refratários, Diss. Mestrado, Universidade Federal de S. Carlos, SP (2002) $144 \mathrm{p}$.

[11] A. Nishikawa, Technology of Monolithic Refractories, Plibrico Japan Co., Ltd., Tokyo, Japão (1984) 83-17

[12] J. R. Garcia, I. R. Oliveira, V. C. Pandolfelli, Processo de Hidratação e os Mecanismos e Atuação dos Aditivos Aceleradores e Retardadores de Pega do Cimento de Aluminato de Cálcio, Cerâmica 53 (2007) 42-56.

(Rec. 16/02/2009, Ac. 17/04/2009) 